iron in powder form. These values were obtained by a resonance method in which a special photoelectric relay reversed the direction of the magnetising field as the oscillating system passed through its zero position.

Again, Ray-Chaudhuri ${ }^{2}$ has published the values $1.008,1.016$ and $1.022 \mathrm{~m} / \mathrm{e}$ for $\mathrm{Fe}_{3} \mathrm{O}_{4}, \mathrm{Fe}_{2} \mathrm{O}_{3}$ and $\mathrm{NiO} \cdot \mathrm{Fe}_{2} \mathrm{O}_{3}$, respectively, with a possible error of 2 per cent. These substances were used in powder form packed inside thin glass tubes. A resonance method with an apparatus similar to that used by Sucksmith in his measurements with paramagnetic substances was employed, the apparatus being evacuated to give large resonance oscillations. It is, however, desirable to consider the theoretical grounds on which the ratio may conceivably be greater than $m / e$. For any electron system, the ratio is accurately given by the expression $\frac{1}{g} \cdot 2 \cdot \frac{m}{e}$, where $g$ is the Lande splitting factor, which is equal to $I$ for purely orbital motion and equal to 2 for spin motion alone. If ferromagnetism is due entirely to electron spin, then the ratio must be $m / e$, but if due to an electron system which is distorted by the fields of neighbouring atoms, it is suggested that $g$ may lie between 1 and 2 , the ratio being correspondingly increased. Again, van Vleck has suggested that two types of ion with $g$ values of $3 / 2$ and 2 may be simultaneously present in the iron lattice and thus give an effective value of $g$ less than 2 .

A measurement of great interest in this connexion is that of Coeterier on pyrrhotite, which shows well-known ferromagnetic peculiarities; this substance in powder form gave a value of 0.63 for $g$ by the method outlined above. Inglis has shown, on the basis of a simple model in which the orbital momenta of the effective electrons are orientated antiparallel to their spins, that the theoretical value for $g$ is $2 / 3$. It is, perhaps, noteworthy that the experimental value of the ratio is thus somewhat higher than the theoretical value, so that perhaps Coeterier's value for iron is also a little too high, but incomplete orientation, as suggested by Inglis, would also account for this difference.

In the case of simple paramagnetic compounds of the rare earth and iron groups, we have fairly definite knowledge of the $g$ values for the appropriate ions based on spectroscopic data. The direct determination of the gyromagnetic ratio for such substances is a matter of extreme difficulty, but such measurements have been successfully made by Sucksmith, who finds satisfactory agreement between the calculated and experimental values. The limits of experimental error were about 6 per cent, but, in view of the great experimental difficulties, Sucksmith was fortunate to get measurements at all. Therefore, the suggestion in a recent article by Barnett ${ }^{3}$ that even these most skilful measurements are open to the serious errors supposed peculiar to English work on gyromagnetism is a little difficult to understand.

In conclusion, then, there appears to be no valid reason why theoretical physicists should consider the gyromagnetic ratio for simple ferromagnetic substances, and for simple paramagnetic substances, to be other than $m / e$ and $\frac{1}{g} 2 \mathrm{~m} / \mathrm{e}$, respectively, in the present state of our knowledge.

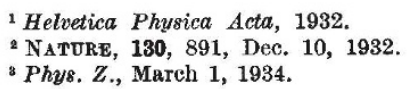

\title{
Research in Australia and New Zealand
}

$\mathrm{W}$ HEN the prices of wheat and wool fell calamitously four years ago, Australia found herself on the verge of economic collapse, and every State department was compelled to tighten its belt in order to avert a general disaster. Among them, the Commonwealth Council for Scientific and Industrial Research discovered some economic truths for which it had not been consciously seeking, and it is now both suffering from, and benefiting by, its discoveries*. It is an undoubted fact that under boom conditions, research is liable to become far more costly than it need be ; a successful investigation may well yield a continuous profit of 1,000 per cent or more on the original capital outlay, and rapidly lead to the initiation of a host of superfluous and hopeless projects. These are the first to be weeded out when contributions to research are curtailed. The Australian Research Council deserves sympathy for the enforced curtailment of its activities, but

* Seventh Annual Report of the Council for Scientific and Industrial Regearch for the year ended 30th June. (Canberra: Commonwealth Government Printer, 1933.) 38. 8d. congratulation for making immediate use of adversity by pressing forward existing schemes for inter-State co-ordination and imperial co-operation in agricultural research. Proposals for establishing a Commonwealth organisation in agricultural and pastoral research were put forward seven years ago, but in view of the wide divergence of interests between the different States and the great distances separating the chief research institutions, it is doubtful how far those proposals would have materialised in the absence of the pressure exerted by recent economic events. In making grateful acknowledgment of the assistance of the now defunct Empire Marketing Board, the Council emphasises the inestimable services performed by the Board in bringing research institutions in different parts of the Empire into close touch with one another.

The report of the Council for the past year, although not recording any outstanding new results of research, gives some very striking figures illustrating the cash returns that have been, and 
may be obtained from the application of scientific research to agriculture in Australia. Thus the complete solution of the problem of 'bitter pit' in apples-a disease found to be associated with immaturity at picking time-has resulted in a saving of $£ 100,000$ per annum to the Australian export trade. Root rots and smut of wheat cause losses of more than $£ 1,000,000$ a year, and already considerable progress has been made in controlling these diseases. Great strides have in the past been made in the field of plant breeding, and have enabled Australia to become one of the chief wheat producing countries of the world, and it is pointed out that further work which might result in an average increase in quality equal to a penny a bushel would now bring an annual return of

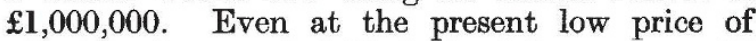
wheat, an increased yield of a bushel an acre would mean more than $£ 3,000,000$ added to the value of the Australian crop. It is true that many of these savings have yet to be made, but it is already obvious that the Council is paying very satisfactory dividends on its annual expenditure of about $£ 100,000$.

Australia's greatest problem is the shortage of water, which limits the natural expansion of both her great industries-wheat and wool production. Progress in the past has depended on the conquest of drought; plant breeding has enabled farmers to produce a bushel instead of half a bushel of wheat for every inch of rain, and animal breeding has enormously increased the yield of wool per sheep from the specially bred merino strains. Progress in the immediate future will involve the consolidation of the position already won, by improving the quality and hardiness of drought-resistant wheats and by maintaining, on dry pasture lands often of indifferent quality, the high wool yield of which the modern merino is capable.

This presents problems of great interest. Apart from the question of drought, there is the greater demand made on soil minerals to produce increasing quantities of wool, and areas once regarded as fertile are incapable of producing the maximum yields that are now possible, and economically essential. In particular, the question of the sulphur metabolism of sheep has come into prominence. Wool consists of keratin, which contains a high proportion of sulphur, and it has so far been assumed that the sulphur needed for the growth of wool must be supplied as cystine. Since the amount of cystine produced by pastures is limited, investigations have been made on the effects on wool production of adding sulphur in other forms to the diet, but without any significant result. The importance of the problem, however, is apparent, and emphasises the imperative need of co-ordinating research on animal breeding and nutrition. It is useless to breed for still higher yields of wool, if the sheep cannot procure the necessary materials for making the wool.

Drought is also being combated by large-scale irrigation schemes, of which the Murray River scheme is perhaps the best known. Its object is to develop a dried fruit industry and involves problems of adjusting a human community to a new environment besides those bearing on irrigation engineering and costs, soil properties, fruit culture and processing, and the control of old and new pests. From its comprehensive nature, the work can only yield results gradually, but it deserves special notice as illustrative of the modern trend of agricultural research programmes - to consider each problem in its intimate relation to all others, biological, chemical, economic and social.

Australian research, under the influence of the slump, is recovering from the first flush of its early triumphs, and one can read between the lines of the Council's report the unexpressed conviction that future progress, although certain, will demand patience, and the realisation by all concerned that the science of the land is one the secrets of which are too deep and complex to be solved except by the corporate action of its many branches.

A striking feature of the work of the New Zealand Department of Scientific and Industrial Research* is that much of it is directed towards the more efficient application of science as a weapon in the struggle to preserve a distant market. As might be expected, most of its activities are connected with agriculture, and one of its first tasks is to keep constantly informed of the changing food fashions of industrial England. The Department works in close co-operation with research organisations such as the Low Temperature Research Station, the Imperial Mycological Institute and the Imperial Agricultural Bureaux in England, and several of its branches maintain liaison officers in London to advise and to secure expert opinion on new lines of produce shipped from the Dominion. Reports received from Britain often determine the lines of research followed in New Zealand.

For example, it was learnt-what is perhaps not realised in Britain itself-that people here are showing an increasing preference for butter with a distinct lactic flavour, and consequently the attention of the Dairy Research Institute was directed towards discovering how this flavour can be obtained-not so much in fresh butter as in butter that has travelled for six weeks in cold storage. The investigation has shown that the required flavour can be obtained by using the highest quality cream. It is interesting to read that "overseas buyers showed themselves remarkably sensitive to salt. . . . It is well known that certain districts in Britain vary in their preferences for degree of saltiness in butter, hence it is incumbent on local buttermakers to study the needs of their special markets before adding salt". We wonder if the British farmer is advised to study the respective idiosyncrasies of London and

* N.Z. Department of Scientific and Industrial Research. Seventh Annual Report for the year 1932-33. (Wellington: Government Printer, 1933.) 28. 6d. 
Manchester with the same care as the New Zealander!

Again with an eye to the British market, a considerable amount of new work has been carried out on the refrigerated transport of fruit, and it has now been found possible to deliver New Zealand plums in London in excellent condition ; attempts to transport lettuces, tomatoes and passion-fruit, however, have been unsuccessful. An investigation which showed that two varieties of apple-Cox's Orange and Jonathan-travel much better at a carrying temperature of $2^{\circ} \mathrm{F}$. above that hitherto used $\left(33^{\circ}-35^{\circ}\right)$ indicates the enormous scope for detailed research that still remains in the realm of cold storage. It is stated that the present inadequate understanding of the meaning of maturity is one of the greatest obstacles to the progress of refrigerated fruit transport.

In 1932, New Zealand exported about $12,000,000$ pickled pelts-an important by-product of the frozen meat industry. The pelt market is very difficult to accommodate, as different buyers have very different views on what are the most desirable qualities in pelts. Since it is impossible to manufacture economically and at the same time satisfy every buyer, research has been directed along the eminently practical lines of making experimental shipments of pelts and discovering their relative values through reports prepared by the New Zealand Pelt Committee in London. Such research is bound to be costly, but it affords a good illustration of the direct way in which New Zealand is attacking practical problems with the closest co-operation between the buying and selling sides of industry. The programme of the Leather Research Association is largely based on the reports received from the Committee in London.

Active research, in collaboration with the English parasite farm at Farnham Royal, and with the help of the Empire Marketing Board, has been carried out on the elimination of noxious weeds. Particular attention has been paid to the ragwort seed-fly and to the piripiri saw-fly, and the value of both parasites-especially the former-in checking the spread of the weeds has been established. The gorse-seed weevil has been effective in the south only, as the flowering season of gorse in the north does not coincide with the weevil's period of activity. The use of the Buprestid beetle against blackberry has had to be abandoned, as it was beginning to attack apple trees, while the blackberries sometimes survived. New Zealand is thus discovering both the possibilities and pitfalls of this modern method of biological control.

The unglamorous but, for the future of agriculture, fundamentally important task of soil survey is continually being extended. In recent years much valuable information has been obtained on the cause and cure of bush-sickness, a disease closely related to the soil type of the pastures grazed by affected animals. The interesting fact has emerged that this iron-deficiency disease is caused by a lack of available iron in the soil itself, rather than in the vegetation, the animals obtaining an essential part of their iron by ingesting soil along with the grass. The diseases can be controlled by giving limonite licks, but the most complete cure has been obtained with drenches prepared from the soil of a healthy pasture, suggesting that iron deficiency is not the only cause of the ailment. Other cattle ailments have been traced to deficiencies in pastures of magnesium, iodine, calcium and phosphorus.

The work of the Department covers other branches of agriculture, concerned mainly with export produce, as well as geological survey, meteorology and astronomy. In a world abounding in international obstacles to the spread of applied science, it is satisfactory to find that New Zealand and Great Britain at least are co-operating freely to secure the widest application of the results of research to problems affecting the welfare of both. The achievement of that co-operation is perhaps the greatest of the Department's successes.

\section{G. V. JACKS.}

\section{Scientific Aspects of Cooking}

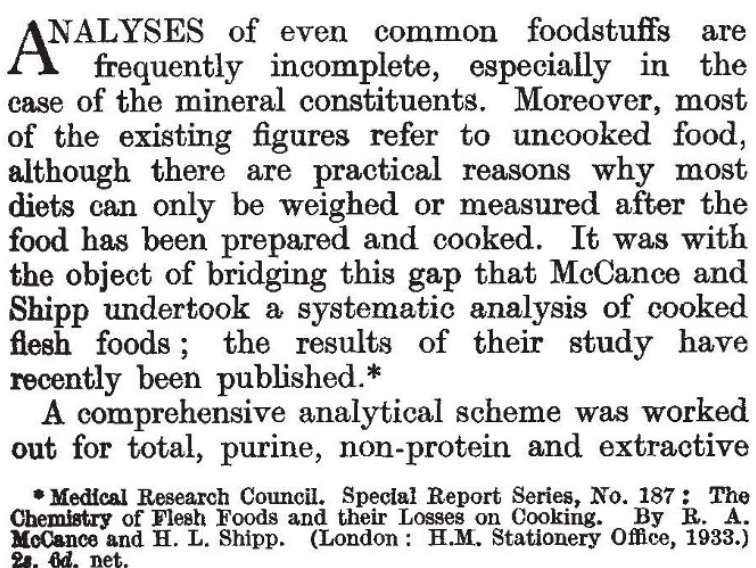
nitrogen, fat, carbohydrate, chloride, total and inorganic phosphorus, sodium, potassium, calcium, magnesium and iron. The chief error was found to lie in the variations of composition of different samples of the same foodstuff : errors of sampling and fortuitous analytical errors were only small. Hence several specimens of each food were analysed whenever possible, but the analyses were not carried out in duplicate. The methods used are described in detail in the report and the analytical figures obtained are set forth in a series of tables and comprise the results of the analyses of 64 samples of fresh fish, 8 of preserved fish, 11 of shellfish, 20 of fresh meat, 8 of preserved meats, 11 of poultry and game, 12 of different animal organs and $a$ few of raw foods. Each figure represents the 